\title{
Pelaksanaan Rujukan Rawat Jalan Pelayanan Kesehatan Tingkat Pertama Pasien BPJS di UPT Puskesmas Martapura Barat
}

\author{
Implementation Of The First-Level Outpatient Health Care Referral Services For BPJS \\ Patients at The UPT Puskesmas Martapura Barat
}

\author{
Nina Rahmadiliyani* ${ }^{1 *}$ Muhammad Khalid Fahrizal Adha ${ }^{2}$ \\ ${ }^{1}$ STIKES Husada Borneo, JI. A. Yani Km 30,5 No.4 Banjarbaru, Kalimantan Selatan \\ ${ }^{2}$ Alumni STIKES Husada Borneo, JI. A. Yani Km 30,5 No.4 Banjarbaru, Kalimantan Selatan \\ *korespondensi :ninarahmadiliyani@gmail.com
}

\begin{abstract}
Health service is implemented gradually since the first level, second level (regional/ city general hospital) which can only be accessed through referral from first level of health service, the third level (provincial/central general hospital) which can only be accessed through referral from first or second level health service, with exception of emergency situation, problem specialty in the regulation of Healthcare Social Security Administrator. This study aims to analyze the implementation of the first-level outpatient health care referral services for BPJS patients at the UPT Puskesmas Martapura Barat. This research uses qualitative research method with case study approach, conducted in the working area of UPT Puskesmas Martapura Barat, using in-depth interviews data collection techniques to two general practitioners, heads of puskesmas, drug managers, nurses, midwives and JKN managers. The results of this study indicate that the reference policy of the UPT Puskesmas Martapura Barat is SK based on the MoU regulated by BPJS, and there is also a diagnosis of BPJS that should be handled by puskesmas, UPT Puskesmas Martapura Barat is still short of doctors, the availability of medicines contained in puskesmas is still a lot of drug shortage, the completeness of health equipment facilities at the puskesmas in general is sufficient, but still needs to be improved, and there are still patients asking for referrals.
\end{abstract}

Keywords: BPJS Health, Referral System

\section{Pendahuluan}

Berdasarkan UU No 40 tahun 2004 Sistem Jaminan Sosial Nasional (SJSN) menetapkan 5 (lima) program jaminan sosial, salah satunya adalah Jaminan Kesehatan Nasioanal atau yang disingkat dengan JKN. JKN adalah jaminan sosial yang diselenggarakan secara nasional dengan tujuan untuk memberikan perlindungan kesehatan dalam bentuk manfaat pemeliharaan kesehatan dalam rangka memenuhi kebutuhan dasar kesehatan yang diberikan kepada setiap orang yang telah membayar iuran atau iurannya dibayar oleh pemerintah (1).

Badan Pelaksana Jaminan Sosial atau yang disingkat BPJS Kesehatan sebagai badan pelaksana merupakan badan hukum yang dibentuk untuk menyelenggarakan program jaminan kesehatan untuk seluruh masyarakat indonesia (2). Manfaat JKN BPJS kesehatan meliputi pelayanan kesehatan tingkat pertama yaitu pelayanan kesehatan non spesialistik dan pelayanan kesehatan rujukan tingkat lanjutan yaitu pelayanan kesehatan mencakup rawat jalan dan rawat inap. Pelayanan kesehatan dilaksanakan secara berjenjang dimulai dari pelayanan kesehatan tingkat pertama, pelayanan kesehatan tingkat kedua (rumah sakit umum kabupaten/kota) hanya dapat diberikan atas rujukan dari pelayanan kesehatan tingkat pertama, pelayanan kesehatan tingkat ketiga (rumah sakit umum propinsi/pusat) hanya dapat di berikan atas rujukan dari pelayanan kesehatan tingkat kedua atau tingkat pertama, kecuali pada keadaan gawat darurat, kekhususan permasalahan aturan BPJS Kesehatan (3).

Menurut Permenkes No 71 tahun 2013 Fasilitas Kesehatan tingkat pertama terdiri dari puskesmas atau yang setara, praktik dokter, praktik dokter gigi, klinik pratama atau yang setara, rumah sakit kelas D Pratama atau yang setara. Fasilitas kesehatan tingkat pertama yang bekerja sama dengan BPJS 
kesehatan harus menyelenggarakan pelayanan kesehatan yang komprehensif. Pelayanan kesehatan komprehensif berupa pelayanan kesehatan promotif, preventif, kuratif, rehabilitatif, pelayanan kebidanan, dan pelayanan kesehatan darurat medis, termasuk pelayanan penunjang yang meliputi pemeriksaan laboratorium sederhana dan pelayanan kefarmasian sesuai dengan ketentuan peraturan perundang-undangan (2).

Sistem Rujukan adalah penyelenggaraan pelayanan kesehatan yang mengatur pelimpahan tugas dan tanggung jawab pelayanan kesehatan secara timbal balik baik vertikal maupun horizontal, maupun struktural dan fungsional terhadap kasus penyakit atau masalah penyakit atau permasalahan kesehatan. Setiap rumah sakit mempunyai kewajiban merujuk pasien yang memerlukan pelayanan di luar kemampuan pelayanan rumah sakit (4).

Pada tahun 2014 ada 144 jenis penyakit yang bisa dilayani Fasilitas Kesehatan Pertama BPJS, namun pada 2017 sudah meningkat lagi jumlahnya yaitu 155 jenis penyakit yang bisa di diagnosa dan ditangani FKTP. Setiap peserta harus memperoleh pelayanan kesehatan pada Fasilitas Kesehatan Tingkat Pertama (FKTP) tempat Peserta terdaftar. Fasilitas kesehatan tingkat pertama (FKTP) yaitu Puskesmas, praktik dokter perorangan, praktik dokter gigi, klinik umum dan rumah sakit kelas $D$ Pratama. Jika di suatu daerah tidak ada dokter, maka BPJS Kesehatan dapat bekerjasama dengan bidan dan praktik perawat untuk memberikan pelayanan kesehatan dasar.

Masyarakat yang akan berobat ke rumah sakit umum pemerintah dengan kartu BPJS harus mendapat rujukan dari dokter klinik/puskesmas, atau rumah sakit umum daerah. Masyarakat yang datang ke rumah sakit sekunder, akan dilayani jika sudah mendapatkan rujukan dari pelayanan kesehatan primer, sesuai dengan Permenkes No. 001 tahun 2012 Tentang Sistem Rujukan Pelayanan Kesehatan Perorangan. Aturan ini diterbitkan agar Program JKN dapat berjalan baik.

Berdasarkan data BPJS tahun 2017 Desember 2017 didapat kepesertaan BPJS berjumlah 187.982 .949 (75\%) dari total penduduk indonesia yang sudah menjadi peserta BPJS

Data dari Puskesmas Martapura Barat tahun 2016 didapat angka rujukan pasien BPJS ke fasilitas kesehatan tingkat II sebanyak 338 rujukan, meningkat di tahun 2017 sebanyak 1.125 rujukan.

Observasi yang dilakukan di Puskesmas Martaputa Barat, diperoleh data kunjungan pasien BPJS tahun 2016 sebanyak 3.227 orang, dengan total rujukan sebanyak 338 rujukan (10\%). Pada tahun 2017 kunjungan pasien BPJS meningkat sebanyak 4.267 orang, dengan total rujukan sebanyak 1.125 rujukan (26\%). Data tersebut menunjukkan bahwa jumlah rujukan pada tahun 2017 belum ideal.

Latar belakang diatas menjadi dasar pertimbangan peneliti untuk fokus pada pertanyaan dengan rumusan masalah bagaimana pelaksanaan Rujukan Rawat Jalan Pelayanan Kesehatan Tingkat Pertama Pasien BPJS di UPT Puskesmas Martapura Barat?

\section{Metode Penelitian}

Penelitian ini menggunakan metode penelitian kualitatif dengan pendekatan studi kasus. Lokasi penelitian bertempat dibagian pelayanan dan loket pendaftaran pasien BPJS di Puskesmas Martapura Barat. Subjek penelitian adalah adalah dokter umum sebanyak 2 orang sedangkan kepala puskesmas, perawat, bidan, pengelola obat, dan pengelola JKN sebanyak 5 orang.

Pada penelitian ini menggunakan jenis wawancara mendalam dan menggunakan metode pencatatan langsung, alat tulis dan tape recorder.

Analisis data kualitatif dilakukan terhadap data empiris yang terkumpul yang berupa kumpulan kata-kata informan. Analisis data menggunakan alur dari miles dan Huberman yang terdiri dari tiga tahap, yaitu reduksi data, penyajian data, dan penarikan kesimpulan/verifikasi (5).

\section{Hasil Penelitian \\ Implementasi Aspek Kebijakan Rujukan di Puskesmas, Terkait Dengan Proses Pelaksanaan Rujukan Pasien BPJS}

Aspek kebijakan rujukan puskesmas berdasarkan apabila pasien tidak mampu ditangani puskesmas maka pasien itu dirujuk. 
Berdasarkan wawancara informan 1 menyatakan bahwa :

Kebijakan rujukan puskesmas berdasarkan MoU, rujukannya ke RS mana itukan berdasarkan MoU nya. Setelah itu kriteria rujukannya kita mengacu kemana. Nah kalonya ketetapan BPJS ada diagnosa yang harus bisa ditangani oleh puskesmas. $\mathrm{Nah}$ berarti itu harus tuntas. Kalau misalkan dirujuk ada alasannya kenapa harus dirujuk. Jadi pasien itu dirujuk apabila puskesmas tidak bisa menangani"

Alur rujukan pasien. Hal ini dinyatakan oleh informan 2 yaitu

"Pasien datang ke puskesmas, kemudia pasien mendaftar diruang pendaftaran, setelah itu kita lihat atau kita periksa diruang pemeriksaan, apabila masuk dalam kriteria rujukan maka dirujuk kerumah sakit. Kalonya. Bila pasien gawat darurat yang dirujuk didampingi, kalau tidak gawat darurat langsung ke poli misalkan rawat jalan, tinggal dibikinkan rujukannya sesuai sudah diperiksa pasiennya kan, sesuai dikasih rujukan maka dikirim langsung"”.

Ketersediaan Dokter Dalam Memberikan Pelayanan Kesehatan Yang Terdapat di Puskesmas, Terkait Dengan Proses Pelaksanaan Rujukan Pasien BPJS

Wawancara terhadap informan menyatakan bahwa:

"Dokter yang terdapat di Puskesmas sebanyak 2 orang itu sangat kurang karena fungsi puskesmas selain sebagai tempat pengobatan, Puskesmas juga berfungsi sebagai promotif preventif sehingga setiap bulan itu harus bergantin, yang satu stand by di kegiatan pelayanan luar, yang satu stand by di puskesma.

Begitu pula wawancara informan 3 yang mengatakan :

"Sebenarnya masih belum cukup untuk dokter umum ya, perlu tambahan satu orang dokter umum lagi, karena dokter kan kadangkadang ada kegiatan luar kaya posbindu, posyandu lansia itu perlu dokter. Sedangkan dipuskesmas dokter yang bersangkutan ada kesibukan jadi paling tidak nambah satu lagi".

\section{Ketersediaan Obat-obatan Yang Terdapat di Puskesmas, Terkait Dengan Proses Pelaksanaan Rujukan Pasien BPJS \\ Wawancara informan 2 mengatakan} bahwa:

"Ketersedian obat di Puskesmas masih kurang karena memang kriteria yang di ajukan BPJS ini ini tidak sesuai dengan formularium yang diajukan oleh dinas, bila kedepannya belum tau perencanaan dinas seperti apa, yang ini kami banyak stok kosong obat. Kemarin kami sudah bertemu BPJS, jadi kami sampaikan banyak obat yang kosong. Jadi tidak bisa dituntaskan, istilahnya diagnosa yang harus dituntaskan oleh puskesmas itu jadi tidak tuntas karena keterbatasan obat"

Pada wawancara informan 4 didapatkan hasil bahwa :

"Obat yang terdapat tidak mencukupi, karena banyak keluhan pasien obat tidak lengkap, kadang-kadang juga sering kosong"

\section{Kelengkapan Dari Fasilitas Alat Kesehatan di Puskesmas, Terkait Dengan Proses Pelaksanaan Rujukan Pasien BPJS} bahwa:

Wawancara informan 4 mengatakan

"Fasilitas puskesmas masih jauh dari yang kita harapkan ya, contohnya di fasilitas laboratorium hanya ada alat mikroskop untuk pemeriksaan kimia darah dasar saja. Tapi sebenarnya kita harus ada seperti alat analyzer, begitupun juga alat di ruang tindakan. Masih banyak yang kita perlukan, section belum ada juga. Alat-alat yang lain pun masih kurang"

Pada wawancara informan 5 didapatkan hasil bahwa :

"Fasilitas di Puskesmas masih Kurang, karena dipuskesmaas itu banyak alat-alat kegawat daruratan kurang, karena kalau alat tidak ada pasien banyak dirujuk oleh 
dokter dokter, section farm kami nggak punya, alat sedot lambung juga, alat kesehatan juga banyak rusak seperti alat pemeriksaan telinga dan mata rusak"

\section{Permohonan rujukan oleh Pasien BPJS \\ Pada wawancara informan didapatkan hasil bahwa : \\ "Terdapat pasien BPJS yang menginginkan dirujuk karena menganggap bahwa puskesmas itu kurang bagus obatnya dan juga dokternya kurang kompeten"}

Pada wawancara informan 7 didapatkan hasil bahwa :

"Saat ini terdapat 2 cara, ada yang meminta rujukan tetapi pasien itu sudah dirumah sakit baru meminta Ada juga pasien meminta rujuk pasien itu belum pernah berobat tapi meminta rujuk. Jadi untuk pasien belum pernah berobat atau belum pernah ke rumah sakit itu harus mendapatkan pelayanan terlebih dahulu dipuskesmas. Bila pasien itu tidak harus dirujuk harus mendapatkan pelayanan dulu dari puskesmas minimal mendapatkan pengobatan dari puskesmas, kecuali sudah sudah mendapatkan pengobatan puskesmas sampai $2 x$ bila tidak ada perkembangan baru kita lakukan rujukan. Tapi tetap kita memberikan pelayanan dulu, tapi pertama kita harus menjelaskan kekeluarga pasien atau pasien itu sendiri bahwa pasien ini tidak perlu dirujuk cukup ditangani oleh puskesmas. Sebenarnya kenapa pasien itu meminta rujuk, itu karena pasien tidak mengerti mengenai masalah rujukan itu sendiri. Kecuali pasien gawat darurat dibawa kerumah sakit harus kita siapkan rujukan"

\section{Pembahasan}

Aspek Kebijakan Rujukan di Puskesmas, Terkait Dengan Proses Pelaksanaan Rujukan Pasien BPJS

UPT Puskesmas Martapura Barat sebagai pemberi kesehatan dasar belum mampu mengimplementasikan peraturan yang berlaku. Ini dibuktikan dengan tingginya angka rujukan ke fasilitas kesehatan tingkat dua yaitu mencapai 1.125 rujukan pada Rumah Sakit Pemerintah melebihi dari standar ketetapan BPJS Kesehatan yaitu
$15 \%$. Seharusnya hal ini tidak bisa terjadi karena di Era JKN, UPT Puskesmas Martapura Barat sebagai Faskes tingkat Pertama harus mampu melaksanakan 155 diagnosa penyakit secara baik dan tuntas.

Salah satu bagian terpenting dalam penyelenggaraan pelayanan kesehatan adalah rujukan kesehatan. Rujukan kesehatan dapat disebut sebagai penyerahan tanggung jawab dari satu pelayanan kesehatan ke pelayanan kesehatan yang lain.

Sistem rujukan adalah suatu sistem penyelenggaraan pelayanan kesehatan yang melaksanakan pelimpahan wewenang dan tanggungjawab atas kasus penyakit atau masalah kesehatan yang diselenggarakan secara timbal balik, baik vertikal dalam arti dari satu strata sarana pelayanan kesehatan ke strata pelayanan kesehatan lainnya, maupun horizontal dalam arti antara strata pelayanan kesehatan yang sama. Sederhananya, sistem rujukan mengatur dariamana dan harus kemana seseorang dengan gangguan kesehatan tertentu memeriksakan keadaan sakitnya (1).

Berdasarkan Permenkes No 01 Tahun 2012 Tentang Sistem Rujukan Pelayanan Kesehatan Perorangan di mana rujukan oleh fasilitas pelayanan kesehatan dimulai dari pelayanan kesehatan tingkat pertama, pelayanan kesehatan tingkat kedua hanya dapat diberikan atas rujukan dari pelayanan kesehatan tingkat pertama, dan pelayanan kesehatan tingkat ketiga hanya dapat diberikan atas rujukan dari pelayanan kesehatan tingkat kedua atau pertama, kecuali dalam keadaan gawat darurat, kekhususan permasalahan kesehatan pasien, pertimbangan geografis, dan pertimbangan ketersediaan fasilitas (6).

UPT Puskesmas Martapura Barat menggunakan pedoman tentang diagnosa penyakit yang mesti di tuntaskan di fasilitas kesehatan tingkat pertama yaitu berdasarkan nota kesepakatan (MoU) dari BPJS yang mesti dituntaskan Puskesmas yaitu 155 diagnosis penyakit.

\section{Ketersediaan Dokter Dalam Memberikan Pelayanan Kesehatan Yang Terdapat di Puskesmas, Terkait Dengan Proses Pelaksanaan Rujukan Pasien BPJS} Ketersediaan dokter di UPT Puskesmas Martapura Barat telah memenuhi 
standar Permenkes No. 75 tahun 2014 tentang Puskesmas bahwa puskesmas setidaknya memiliki 2 dokter umum dan 1 dokter gigi. Walaupun ketersediaan dokter di UPT Puskesmas Martapura Barat sudah memenuhi standar, UPT Puskesmas Martapura Barat masih kekurangan dokter karena Dokter puskesmas juga sering ada kegiatan diluar, penyuluhan kedesa, dan pendampingan akreditasi. Sehingga membuat beban kerja dokter lebih berat dan pelayanan puskesmas menjadi tidak maksimal.

Kekurangan dokter membuat pelayanan puskesmas menjadi tidak maksimal, apalagi setiap tahun kunjungan pasien UPT Puskesmas Martapura Barat meningkat. Hal ini bisa berpengaruh terhadap pasien yang menganggap puskesmas pelayanannya menjadi kurang kompeten dan bisa berpengaruh terhadap pasien yang meminta rujukan.

Berdasarkan Permenkes No. 75 Tahun 2014 Pasal 16 ayat 2 yaitu Jenis dan jumlah tenaga kesehatan dan tenaga non kesehatan dihitung berdasarkan analisis beban kerja, dengan mempertimbangkan jumlah pelayanan yang diselenggarakan, jumlah penduduk dan persebarannya, karakteristik wilayah kerja, luas wilayah kerja, ketersediaan fasilitas pelayanan kesehatan tingkat pertama di wilayah kerja dan pembagian waktu kerja (7).

Oleh karena itu berdasarkan Permenkes No.75 Tahun 2014 Pasal 16 ayat 2 , menyatakan bahwa dokter bisa ditambah dengan mengananlisis standar beban kerja agar mampu meningkatkan pelayanan puskesmas menjadi maksimal (7).

Sedangkan mengenai ada atau tidak adanya dokter di puskesmas karena berhalangan hadir, berdasarkan wawancara dengan informan 5 dan informan 7 menyebutkan jika tidak ada dokter di Puskesmas maka pasien itu disuruh ke puskesmas lagi atau menunggu pada saat dokter ada. Namun berbeda pada wawancara terhadap informan 1, 2 dan 6, dari wawancara tersebut mereka menyebutkan bahwa jika dokter berhalangan hadir maka yang melakukan pelimpahan pasien adalah perawat, namun mereka tetap on call atau konsul ke dokter. Namun Informan 2 juga mengatakan kadang pasien disuruh nunggu pada saat dokter ada.
Masalah ketidakhadiran dokter adalah ketika dokter berhalangan hadir ke puskesmas yang menggantikan pelimpahan wewenang adalah perawat. Walaupun kadang perawat tetap konsul ke dokter, hal ini tetap tidak boleh terjadi karena berdasarkan UU No. 36 tahun 2009 pasal 63 ayat 4 tentang Kesehatan yang berbunyi pelaksanaan pengobatan dan atau keperawatan berdasarkan ilmu kedokteran atau ilmu keperawatan hanya dapat dilakukan oleh tenaga kesehatan yang mempunyai keahlian dan kewenangan untuk itu. Yang mana berdasarkan pasal ini keperawatan merupakan salah satu profesi atau tenaga kesehatan yang bertugas untuk memberikan pelayanan kepada pasien yang membutuhkan pelayanan keperawatan saja (8).

Menurut Permenkes No 01 Tahun 2012 Tentang Sistem Rujukan Pelayanan Kesehatan Perorangan, bidan dan perawat hanya dapat melakukan rujukan ke dokter dan atau dokter gigi pemberi pelayanan kesehatan tingkat pertama (6).

Hal ini sejalan teori Zulkarnai Dkk (2001) dalam Nining Thalib (2017) bahwa tingginya rasio rujukan dapat juga disebabkan oleh seringnya dokter Puskesmas memberikan wewenang kepada petugas lain (9).

\section{Ketersediaan Obat-obatan Yang Ada di Puskesmas, Terkait Dengan Proses Pelaksanaan Rujukan Pasien BPJS \\ Ketersediaan obat-obatan} yang terdapat di UPT Puskesmas Martapura Barat masih banyak kekurangan obat dan sering juga kehabisan stok obat, bahkan obat-obat seperti obat batuk dan obat paracetamol saja sering kosong, puskesmas juga kekurangan obat untuk pasien saraf karena kasus rujukan banyak pasien saraf. Hal ini bisa menyebabkan penyakit yang seharusnya tuntas menjadi tidak tuntas.

Menurut Permenkes No. 28 tahun 2014 tentang Pedoman Pelaksanaan Program Jaminan Kesehatan Nasional, pengadaan obat-obatan terutama untuk obat peserta JKN tidak terpisah dengan obat-obatan lain. Pelayanan obat untuk peserta JKN di Fasilitas Kesehatan Tingkat Pertama di lakukan oleh apoteker. Pelayanan obat untuk peserta JKN pada fasilitas kesehatan mengacu pada daftar obat yang tercantum 
dalam Formularium nasional dan harga obat yang tercantum dalam e-katalog obat (3).

Program Jaminan Kesehatan Nasional tidak di memperbolehkan puskesmas untuk melakukan pembelian obat langsung tetapi perencanaan obat atau pengadan obat di lakukan oleh dinas kesehatan, Sejalan dengan pernyataan dokter (informan 1 dan 2) di UPT Puskesmas Martapura Barat bahwa pengadaan obat di puskesmas dilakukan oleh Dinas Kesehatan Kabupaten Banjar. Namun berdasarkan hasil wawancara didapatkan bahwa UPT Puskesmas Martapura Barat masih banyak kekurangan obat bahkan sering kehabisan stok obat, dan juga kurangnya obat untuk pasien saraf karena kasus rujukan banyak pasien saraf.

Menurut UU No. 36 Tahun 2009 Tentang Kesehatan pasal 36 ayat 1, bahwa pemerintah menjamin ketersediaan, pemerataan dan keterjangkauan perbekalan kesehatan terutama obat esensial. Namun dalam kenyataannya, Dinas Kesehatan Kabupaten Banjar sebagai instansi yang bertanggungjawab dalam pemenuhan kebutuhan dan ketersediaan obat-obatan untuk UPT Puskesmas Martapura Barat tidak mampu memenuhi permintaan kebutuhan obat-obatan pasien di puskesmas. Padahal pihak BPJS sendiri sebenarnya sudah membantu secara finansial serta menyerahkan sepenuhnya kepada dinas kesehatan dalam menyediakan obatobatan tersebut. Sedangkan ketika obat-obatan yang dibutuhkan tidak tersedia ataupun stok habis, maka obat-oabatan yang stoknya habis akan diganti dengan obat lain atau pasien disuruh membeli diluar. Namun Apabila obat memang tidak tersedia di puskesmas maka diberi rujukan untuk mendapatkan pengobatan yang sesuai (8).

Merujuk Pedoman Kerja Puskesmas yaitu dalam rangka optimasi pemanfaatan dana obat yang terbatas, Puskesmas dituntut untuk melakukan rasionalisasi penggunaan obat peningkatan mutu preskripsi, dan penggunaan obat secara tepat, efektif, aman, dan efesien.

Penelitian Singarimbun (10) bahwa kesehatan Tingkat Pertama dilakukan oleh apoteker. Pelayanan obat untuk peserta JKN pada fasilitas kesehatan mengacu pada daftar fornas dan harga obat yang tercantum dalam e-katalog obat. Obat-obatan tersebut diajukan oleh tiap Puskesmas ke Dinas
Kesehatan berdasarkan pola konsumsi masing-masing Puskesmas.oleh bahwa ketersediaan obat di puskesmas masih belum mencukupi dan tidak sesuai dengan formularium nasional di Fasilitas Kesehatan Tingkat Pertama yang tercantum dalam Kepmenkes nomor HK 02.02/Menkes/ $523 / 2015$. Terkait jumlah obat yang belum mencukupi standard formularium nasional maka Puskesmas belum mampu memberikan pelayanan yang terbaik.

\section{Kelengkapan Dari Fasilitas Alat Kesehatan di Puskesmas, Terkait Dengan Proses Pelaksanaan Rujukan Pasien BPJS}

Kelengkapan dari fasilitas alat kesehatan di puskesmas, terkait dengan proses pelaksanaan rujukan pasien BPJS di UPT Puskesmas Martapura Barat secara umum sudah mencukupi, namun masih perlu ditingkatkan terutama ketersediaan fasilitas alat di lab masih banyak yang kurang, kemudian alat untuk diruang tindakan masih perlu ditingkatkan, bahkan ada beberapa alat kesehatan yang rusak seperti alat kesehatan pemeriksaan mata dan telinga. walaupun fasilitas alat kesehatan untuk pemeriksaan dasar sudah mencukupi. Sedangkan jika alat untuk menangani pasien tidak tersedia maka pasien akan dirujuk. Kurangnya ketersediaan fasilitas alat kesehatan akan berdampak pada meningkatnya jumlah rujukan yang ada di puskesmas.

Ketersediaan sarana dan fasilitas yang ada di pelayanan kesehatan menjadi salah satu faktor penting dalam mencapai penegakkan diagnosa dan mendukung terselenggaranya pelayanan yang berkualitas bagi masyarakat. Fasilitas alat kesehatan yang memadai dapat meningkatkan kinerja Puskesmas dalam melakukan pemeriksaan kepada pasien dan merupakan suatu keharusan untuk memberikan rujukan akibat keterbatasan sarana tersebut, jika fasilitas dan sarana penunjang kesehatan kurang lengkap maka proses mendiagnosa pada pasien akan terganggu dan hal ini menyebabkan petugas kesehatan harus merujuk pasien kerumah sakit sehingga akan berdampak pada meningkatnya terjadi rujukan di rumah sakit.

Berdasarkan Permenkes No 75 tahun 2014 tentang Pusat Kesehatan Masyarakat peralatan kesehatan di Puskesmas harus 
memenuhi persyaratan yaitu standar mutu, keamanan, keselamatan, memiliki izin edar sesuai ketentuan peraturan perundangundangan dan diuji serta dikalibrasi secara berkala oleh institusi penguji dan pengkalibrasi yang berwewenang (7).

Ketersediaan fasilitas alat kesehatan yang memadai dapat meningkatkan kinerja Puskesmas dalam melakukan pemeriksaan kepada pasien dan merupakan suatu keharusan untuk proses rujukan yang dilakukan akibat keterbatan sarana tersebut, jika fasilitas alat kesehatan kurang lengkap maka proses mendiagnosis pasien akan terganggu dan hal ini menyebabkan petugas kesehatan harus merujuk pasien ke rumah sakit sehingga akan berdampak peningkatan rujukan pasien pada rumah sakit penerima rujukan tersebut (11).

\section{Permohonan Rujukan oleh Pasien BPJS}

Pada pelayanan di Puskesmas bahwa masih ada pasien meminta rujukan karena pasien menganggap puskesmas itu kurang pelayanannya, dan juga ingin mendapatkan pelayanan yang lebih baik. Namun sebagian tenaga medis terutama dokter yang betugas di Puskesmas telah paham atas fungsi gatekeeper sebagai penapis tujukan terkait dengan pasien yang meminta rujukan.

Gatekeepeer merupakan dokter pelayanan primer dalam organisasi managed care yang bekerja untuk mengkoordinasikan pelayanan kepada peserta dan untuk memaksimalkan efisiensi dan efektifitas pelayanna serta berperan mengedalikan penggunaan pelayanan kesehatan dan rujukan peserta program (12).

Berdasarkan Permenkes Nomor 40 Tahun 2012 tentang Pedoman Pelaksanaan Program Jaminan Kesehatan Masyarakat menyebutkan bahwa kendala pelaksanaan Jaminan Kesehatan yang masih terjadi yaitu sistem rujukan belum berjalan secara optimal (13).

Pasien yang meminta rujukan tetapi tidak terdapat indikasi medis untuk merujuk, maka dokter tidak memberikan rujukan dan sebaliknya pasien akan diberikan edukasi dari dokter yang menangani untuk di periksa di Puskesmas (9).

Pasien meminta rujukan atas dasar keperluan atau keinginan perawatan atau pengobatan yang lebih lengkap, namun di UPT Puskesmas Martapura Barat apabila pasien tetap maksa minta rujukan dengan terpaksa puskesmas akan memberikan rujukan dengan persyaratan atas permintaan sendiri walaupun pasien tersebut masih bisa ditangani oleh puskesmas.

\section{Kesimpulan}

Implementasi aspek kebijakan yang menjadi pedoman pelaksanaan rujukan belum berjalan dengan baik karena rasio rujukan melebihi standar ketepatan BPJS, masih terdapat kekurangan dokter puskesmas juga sering ada kegiatan diluar, penyuluhan kedesa, dan pendampingan akreditasi, masih banyak kekurangan obat bahkan sering kehabisan stok obat, dan juga kurangnya obat untuk pasien saraf karena kasus rujukan banyak pasien saraf, Ketersediaan fasilitas alat kesehatan secara umum sudah cukup, namun perlu ditingkatkan karena ada sebagian alat fasilitas kesehatan yang rusak, masih adanya pasien meminta rujukan Atas Permintaan Sendiri (APS) yang mengakibatkan angka rujukan masih tinggi. Hal ini menyebabkan UPT Puskesmas Martapura Barat dalam melaksanakan pelayanan kesehatan belum mampu mengimplementasikan konsep gatekeeper.

\section{Daftar Pustaka}

1. Herlambang, Susatyo. 2016. Manajemen Pelayanan Kesehatan Rumah Sakit. Yogyakarta: Gosyen Publishing.

2. Kementerian Kesehatan Republik Indonesia. 2013. Peraturan Menteri Kesehatan RI Nomor 71 tahun 2013 tentang Pelayanan Kesehatan pada Jaminan Kesehatan Nasional.

3. Kementerian Kesehatan Republik Indonesia. 2014. Peraturan Menteri Kesehatan RI Nomor 28 tahun 2014 tentang Pedoman Pelaksanaan Program Jaminan Kesehatan Nasional, Jakarta.

4. Undang-undang Republik Indonesia nomer 44 tahun 2009 tentang Rumah Sakit.

5. Basuki, Sulistyo. 2010. Metode Penelitian. Jakarta : Penaku.

6. Kementerian Kesehatan Republik Indonesia. 2012. Peraturan Menteri Kesehatan RI Nomor 001 tahun 2012 tentang Sistem Rujukan Pelayanan Kesehatan Perorangan. 
7. Kementerian Kesehatan Republik Indonesia. 2014. Peraturan Menteri Kesehatan RI Nomor 75 Tahun 2014 tentang Puskesmas.

8. Undang-Undang Republik Indonesia Nomer 36 tahun 2009 tentang Kesehatan.

9. Nining, Thalib. 2017. Tinjauan Pelaksanaan Sistem Rujukan Pasien Bpjs Di Puskesmas Gamping I Sleman Yogyakarta Tahun 2017. KTI. Program Studi Perekam Medis Dan Informasi Kesehatan (D-3) Sekolah Tinggi IImu Kesehatan Jenderal Achmad Yani Yogyakarta.

10. Singarimbun. 2017. Pelaksanaan Rujukan Pasien Peserta Jaminan Kesehatan Nasional (JKN) Di Puskesmas Galang Tahun 2017. Skripsi. Fakultas Kesehatan Masyarakat Universitas Sumatera Utara Medan.

11. PAMJAKI (Perhimpunan Ahli Manajemen Jaminan dan Asuransi Kesehatan Indonesia). 2008. Managed Care. Jakarta : PAMJAKI.

12. Kementerian Kesehatan Republik Indonesia. 2014. Peraturan Menteri Kesehatan RI Nomor Nomor 40 Tahun 2012 tentang Pedoman Pelaksanaan Program Jaminan Kesehatan Masyarakat. 